\title{
Archivo y documentos. Patrimonio de La Palma del Condado
}

Juan Castizo Reyes | archivero municipal de La Palma del Condado

URL de la contribución <www.iaph.es/revistaph/index.php/revistaph/article/view/3666>

\section{RESUMEN}

La investigación histórica sobre la provincia de Huelva cuenta con un soporte erudito en el Archivo Histórico de La Palma, que se visibiliza en el alto valor documental de los bienes que posee y que representan una oportunidad para hallar la verdad escondida. No son pocos los aspectos sociales de algunas localidades para los que la única información con la que se cuenta es la que puede encontrarse entre los más de 4.500 legajos que forman la colección.

La siguiente contribución se propone someramente describir la configuración y el alcance temático de una documentación nada desdeñable, que ha tenido y tiene una significación especial en la reciente historiografía andaluza.

\section{Palabras clave}

Archivos | Historia | Huelva (Provincia) | Palma del Condado (La) (Huelva) | Patrimonio documental | 


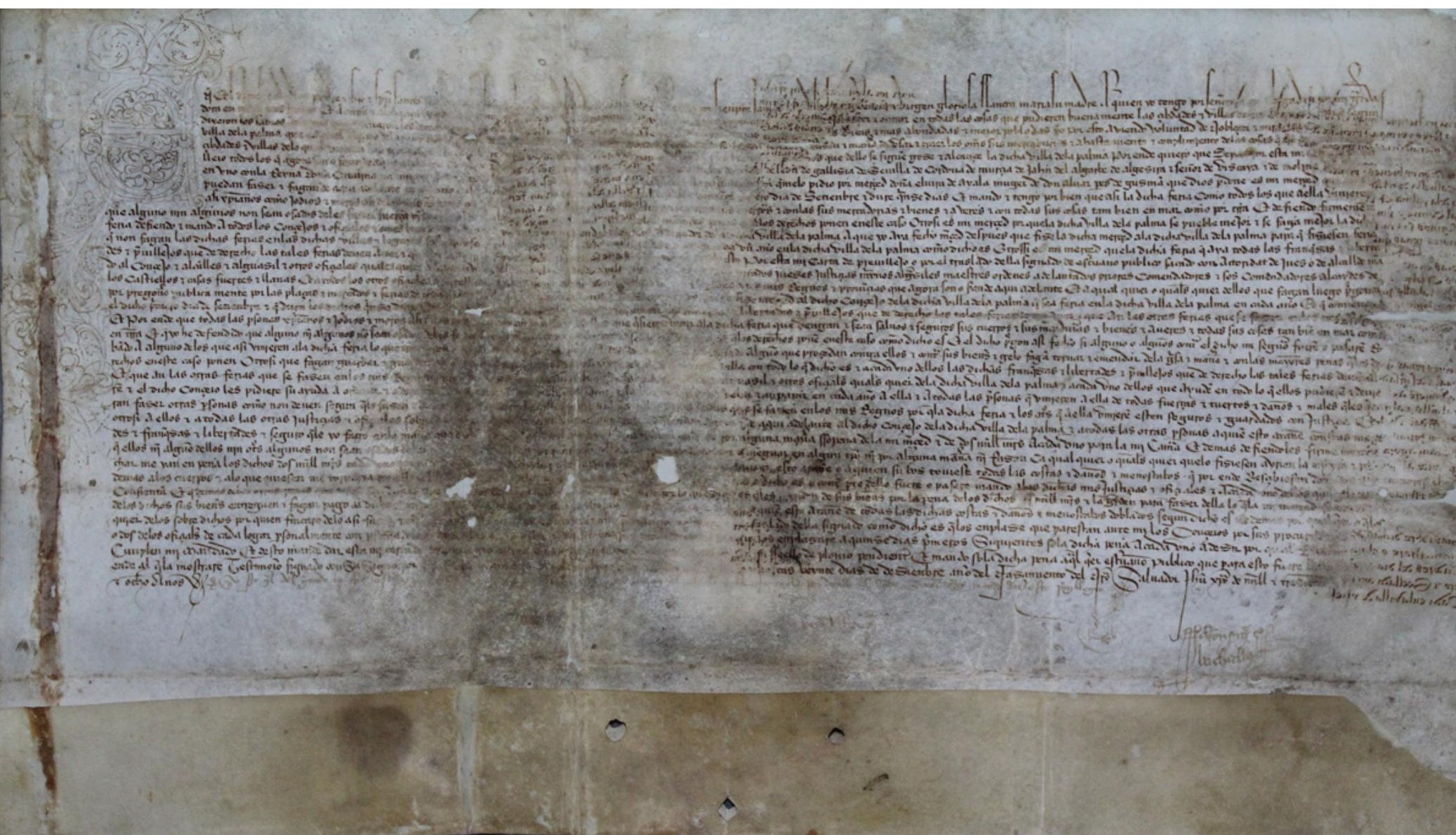

Concesión de merced en carta plomada. 1398, diciembre. Illescas (Toledo). Leg. 71, Secc. Privilegios | fuente Archivo Histórico Municipal de La Palma, de todas las imágenes que ilustran este artículo, si no se indica lo contrario 


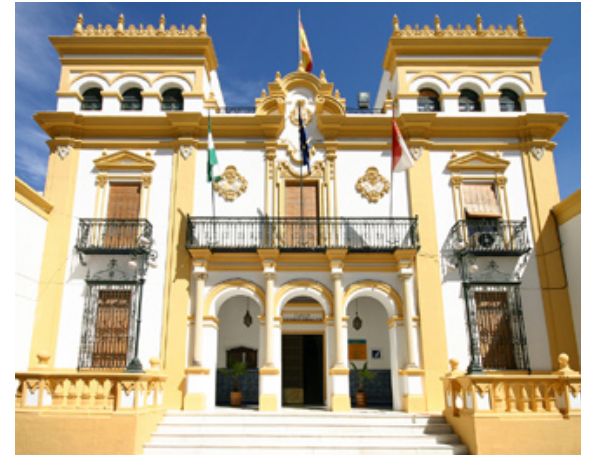

Exterior del edificio del Archivo Municipal de La Palma del Condado | fuente Fototeca Municipal de La Palma del Condado
El edificio regionalista de las antiguas casas consistoriales, que fue primitivo hospital de Santa María entre los siglos XVI al XIX y posteriormente sirvió como escuela pública de niños, es actualmente la sede del Archivo Histórico de La Palma, custodio de una rica documentación que reúne en sendos fondos el legado de la administración municipal junto a los libros de protocolos de los pueblos que componen el distrito notarial que encabeza, esto es: Almonte, Bollullos del Condado, Chucena, Escacena del Campo, Hinojos, Paterna del Campo, Rociana del Condado, Villalba del Alcor y Villarrasa. Esta diversidad geográfica y tipológica lo convierte en un referente documental de primer nivel para la historia y la cultura de la comarca onubense del Condado y, por extensión, del patrimonio documental andaluz.

La tarea continuada de organización archivística iniciado en este archivo hace casi tres décadas garantiza hoy el conocimiento y la difusión de estos fondos así como ha generado ya espacios para la investigación más avanzada. El extenso volumen, formado por más de 5.000 unidades de instalación, permite una aproximación a temáticas de estudio muy diversas que contribuyen a suplir la tradicional carencia de síntesis y monografías históricas para un territorio desprovisto de identidad común que fue la tierra llana de Huelva en el Antiguo Régimen. Las más importantes series documentales del fondo municipal y notarial comparten una cronología que abarcan todo la Modernidad, período durante el cual sentaron sus bases político, económico y social la mayoría de los municipios que guardan aquí buena parte de su pasado. Por su parte, desde el siglo XIX a nuestros días, la masa documental ha crecido exponencialmente, con la agregación de material fotográfico y archivos de personajes literarios locales. Efectivamente, el archivo es fuente para el estudio de la Historia pero su utilización y funcionalidad puede ir desde lo histórico a lo cultural, turístico o didáctico. En cualquier caso, lo ambicioso es que sirva para aglutinar y difundir los recursos disponibles y poder articular un conocimiento cada vez más profundo de nuestro entorno. Muchas tesis, estudios y hallazgos están surgiendo de legajos que son ya referentes únicos de estos fondos, a continuación hacemos relación de algunos de ellos.

\section{EL ARCHIVO, CENTRO DE HISTORIA LOCAL}

El tesoro más antiguo del archivo municipal data de 1398 y es una carta de merced en pergamino que autoriza celebrar una feria en la villa de La Palma, lo que la convierte en uno de los mercados más antiguos fundados en Andalucía (CASTIZO REYES, 1998). Se considera esta fecha inicio de la organización concejil, aunque la formidable serie de Acuerdos Capitulares no arranca hasta el año 1527. Existen cuatro actas que sobresalen por su singularidad histórica: la del 25 de julio de 1593 rubricada por el comisario Miguel de Cervantes, que llega a La Palma para recaudar trigo y aceite para la Armada, dentro del periplo vital que le trajo por otros lugares de Reino 


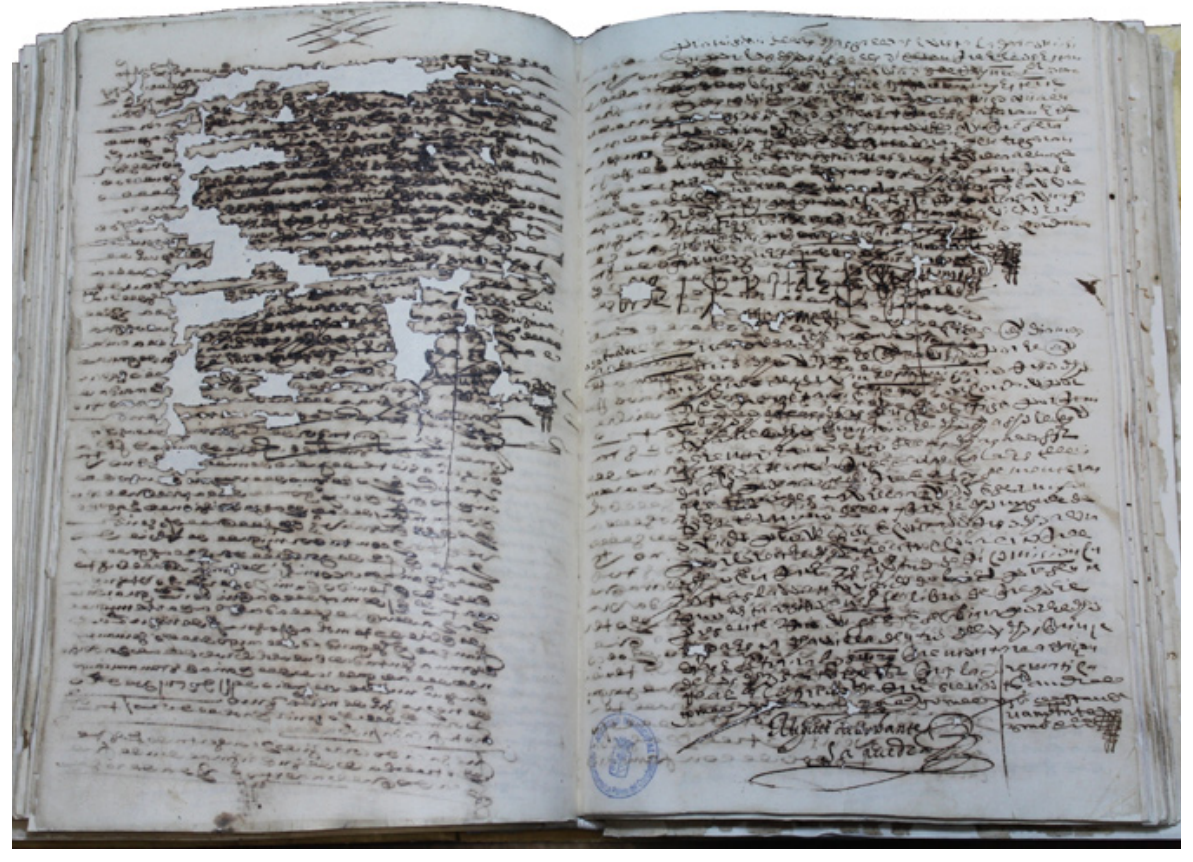

de Sevilla (CASTIZO REYES, 2005); la del 2 de noviembre de 1755, que sirve de crónica de los graves sucesos ocurridos por el gran terremoto el Día de Todos los Santos y que tan devastadoras consecuencias tuvo, entre otros aspectos, en la desaparecida fábrica mudéjar de la iglesia de San Juan Bautista; y un tercer acta del día 5 de septiembre de 1768, que describe con claros tintes ilustrados los actos de bendición del nuevo templo barroco ya construido, hoy declarado BIC. El proceso de desarrollo del ferrocarril por La Palma también se refleja en la documentación municipal (acta capitular que designa la asamblea de políticos y ciudadanos palmerinos en defensa de la vía férrea -RAMíREZ CEPEDA, 1993-) pero sobre todo abunda en la notarial (escrituras de expropiaciones por la poderosa Compañía M.Z.A. a los propietarios de los terrenos de los municipios por los que habría de discurrir la línea Sevilla-Huelva). Hay temas inagotables como la ocupación francesa en la comarca del Condado entre 1810-1812 y su afectación a Doñana y el Rocío (MAYO RODRÍGUEZ, 2011) como recogen muchos autos ejecutivos, civiles y criminales otorgados ante escribanos públicos de Almonte.

\section{EL ARCHIVO, PATRIMONIO CULTURAL}

Sin duda, los estudios sobre religiosidad y cultura acaparan un gran interés en los investigadores de este archivo, que nos acercan a multitud de aspectos relacionados con la vida cotidiana y a elementos identificadores de la comarca, principalmente la viticultura. Los inicios documentados referen-

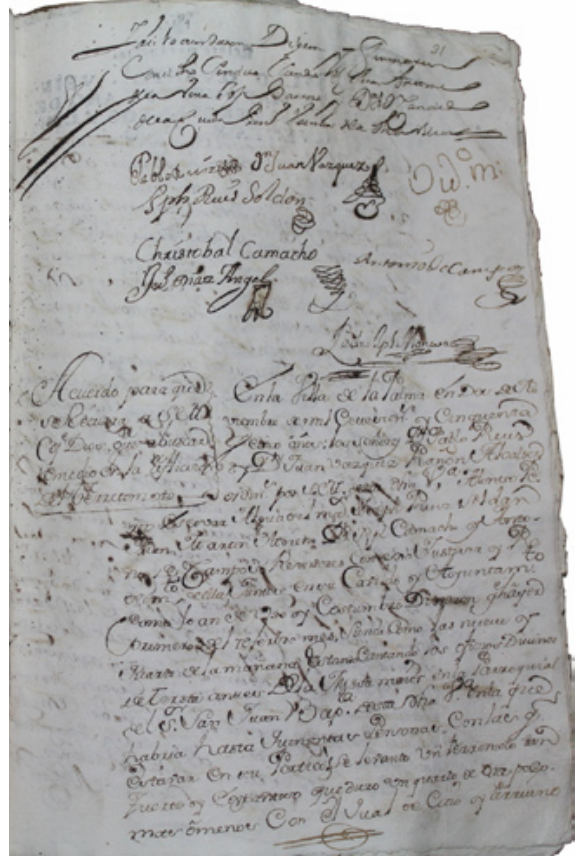

Acta de cabildo del 25 d ejulio de 1593 con certificación firmada por Miguel de Cervantes Saavedra. Leg. 4, Serie Actas Capitulares (15781595) (imagen izquierda)

Acta de cabildo del día 2 de noviembre de 1755 . Leg. 17, fol. 31. Serie Actas Capitulares (1748-1755) (imagen derecha) 
tes a la Virgen del Rocío (o de las Rocinas) corresponden a testamentos de la escribanía de Almonte de 1562 (MUÑOZ BORT, 2012) y los de la Cofradía del Nazareno de La Palma a otro de 1721 (INFANTE LIMÓN; VALIENTE ROMERO, 2012). La asistencia social en hospitales rurales es fundamental para entender la sociedad a partir del siglo XVI (NÚÑEZ ROLDÁN, 2014), o también el período de la posguerra española con la emisión de sellos locales de beneficencia (GUERRA GONZÁLEZ, 2004). Existen destacados trabajos relacionados con las estrategias sociales y construcción de familias de poder en tierras del Condado, como el caso de la Familia Cepeda de Villalba (RAMOS COVANO, 2012), y otros estudios de economía doméstica a partir de escrituras de particiones de bienes o cartas de cuentas de menores en el Almonte y La Palma del siglo XVII (NÚÑEZ ROLDÁN, 2008). Actualmente se encuentran en permanente consulta documentos notariales relativos a la actividad económica generada por dos conventos bajo una misma advocación, San Juan Bautista, pero tan distintas como la Orden Carmelita en Villalba del Alcor y la Orden Tercera de Penitencia de San Juan de Morañina en Bollullos.

\section{EL ARCHIVO, MEMORIA GRÁFICA DEL PUEBLO}

Una fuente de información, conocimiento e interpretación histórica lo constituye el material fotográfico de titularidad municipal conservado desde mediados del siglo XX en negativo y fotolitos. En la actualidad se trabaja en la confección de la Fototeca Municipal a partir de un cuidadoso proyecto de digitalización y catalogación de miles de imágenes que crece continuamente gracias a las aportaciones particulares. Este fondo gráfico posibilita una capacidad de análisis y comprensión de la realidad urbana, comercial, religiosa, festiva y costumbrista sorprendente que sirve para desandar la memoria o recorrer el recuerdo. Se dispone también del archivo audiovisual generado por el canal de televisión local de La Palma, que viene operando desde 1991 y cuenta ya con más de 3.500 documentos en sistema analógico y digital. De la misma manera, el archivo conserva desde 1929 los álbumes de Fiestas Mayores de la ciudad, las de la Fiesta de la Vendimia del Condado, la principal publicación periódica ilustrada de la época más floreciente del comercio del vino en esta comarca, cuya capital económica indiscutible ostentó La Palma con sus célebres bodegas y afamados vinos y licores. En definitiva, trabajamos en nuestros archivos conscientes de ser actores de un patrimonio material e inmaterial, reconociéndonos portadores de ello y con la prioridad de revalorizar y mantenerlo salvaguardado. La comarca del Condado reúne 26 BIC protegidos entre conjuntos históricos, sitios históricos, monumentos y zonas arqueológicas. Sin duda, un territorio que merece ser interpretado y ése, y no otro, seguirá siendo el objetivo preferente del Archivo Histórico de La Palma, porque "interpretar es ayudar a enamorar, y el patrimonio cultural, como el natural, necesita ser querido" (DELIBES DE CASTRO, 1998). 


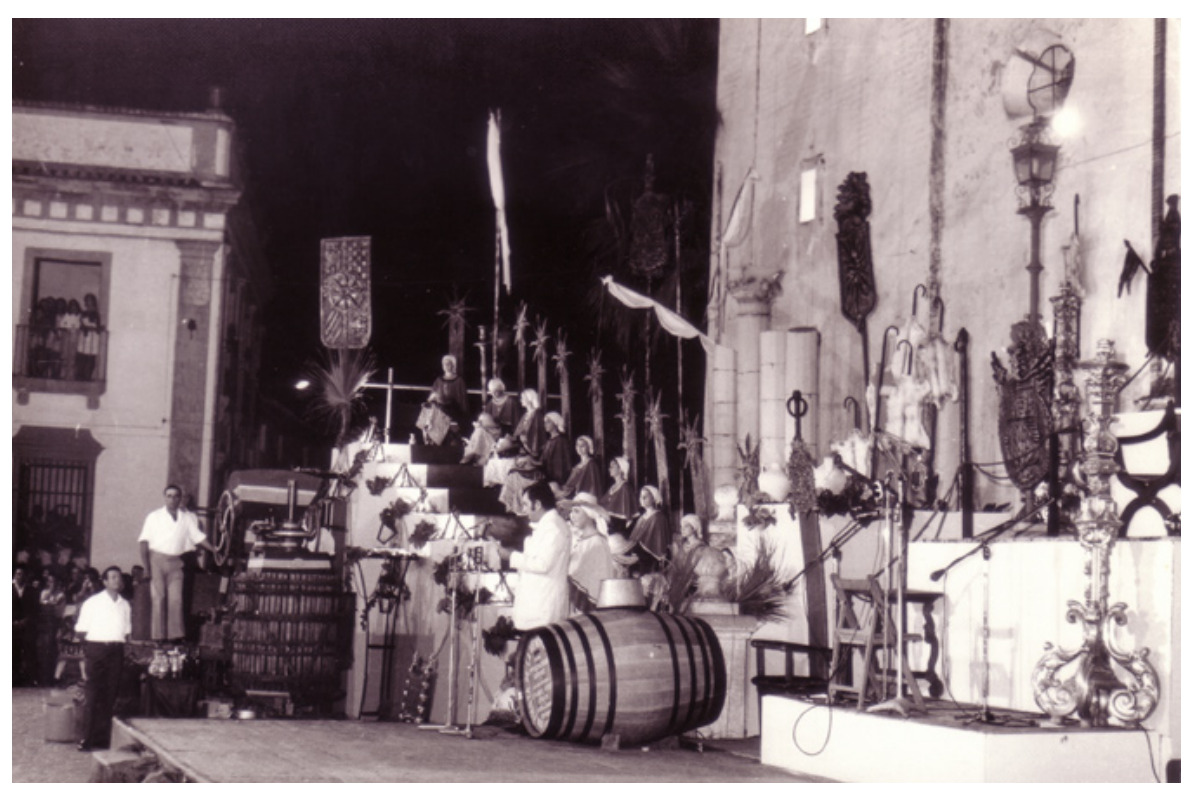

Acto de la XIII Fiesta de la Vendimia del Condado, sábado 22 de septiembre de 1973 | fuente Fototeca Municipal de La Palma del Condado

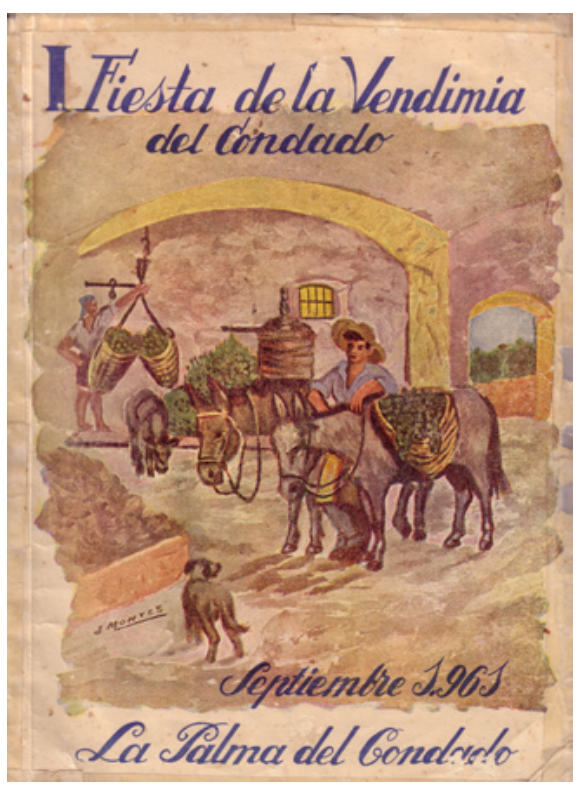

Libro de la I Fiesta de la Vendimia del Condado. Expediente del programa de festejos de la Real Feria de Ganados y Fiesta de la Vendimia. Septiembre de 1961. Leg. 661

\section{BIBLIOGRAFÍA}

- CASTIZO REYES, J. (1998) Una feria para un señorío. En Carta de Privilegio de la Real feria de La Palma. La Palma del Condado: Ayuntamiento, 1998

- CASTIZO REYES, J. (2005) En un lugar de La Palma. En Cervantes en La Palma. Edición fascimilar de folio manuscrito con rúbrica de Miguel de Cervantes Saavedra. 1593, julio, 25. La Palma del Condado: Ayuntamiento, 2005

- DELIBES DE CASTRO, M. (1998) Prólogo. En MORALES MIRANDA, J. Guía práctica para la interpretación del patrimonio: el arte de acercar el legado natural y cultural al público visitante. Sevilla: Empresa Pública de Gestión de Programas Culturales, 1998

- GUERRA GoNzÁlez, J. E. (2004) Asistencia social, Beneficencia y Sanidad en el sello de correos de Huelva y Provincia durante la Guerra Civil Española. Huelva: Colegio Oficial Enfermería de Huelva, 2004

- INFANTE LIMÓN, E., VALIENTE ROMERO, A. (2012) La hermandad de Nuestro padre Jesús Nazareno de La Palma del Condado. Del Barroco a la Guerra Civil. La Palma del Condado: Hermandad de N.P.J., 2012

- MAYO RODRíGUEZ, J. (2011) El Rocío en la Guerra de la Independencia. En Exvoto, n. ${ }^{\circ}$ 0. Almonte: Hermandad Matriz de Ntra. Sra. del Rocío, 2011
- MUÑOZ BORT, D. (2012) El ayuntamiento de la villa de Almonte y la expansión de la devoción a la Virgen del Rocío (siglos XIV-XX). En Exvoto, n. ${ }^{\circ}$ 1. Almonte: Hermandad Matriz de Ntra. Sra. del Rocío, 2012

- NúÑEZ ROLDÁN, F. (2014) El proceso de reducción de hospitales en la Andalucía rural. Los hospitales de Niebla y La Palma (1590-1847). Conflictos, corruptelas y desobediencias. En Erebea, n. ${ }^{\circ}$ 4. Universidad de Huelva, 2014

- NúÑEZROLDÁN, F. (2008) La economía doméstica rural en la Andalucía Barroca. En Actas Congreso Internacional de Andalucía Barroca. $H^{a}$ demográfica, económica y social (Vol. 2. ${ }^{\circ}$ ). Junta de Andalucía, 2008

- RAMíREZ CEPEDA, M. (1993) La gestación de un ferrocarril en La Palma del Condado. La Palma del Condado: Asociación Cultural amigos de La Palma, 1993

- RAMOS COVANO, C. (2012) Familia, poder y representación en Andalucía: los Cepeda entre el Antiguo y el Nuevo Régimen (1700-1850). Universidad de Huelva, 2012 